\title{
A note on organizational structure and environmental liability
}

\author{
Laurent Franckx ${ }^{1}$. Frans P. de Vries ${ }^{2} \cdot$ Ben White $^{3}$
}

Received: 18 March 2019 / Accepted: 3 July 2021 / Published online: 22 July 2021

(c) The Author(s) 2021

\begin{abstract}
This paper employs a multi-task principal-agent model to examine how a corporation's organizational structure and liability rules for environmental damages affect the incentive schemes offered to managers. We derive environmental liability rules for risk averse managers under two alternative organizational structures: a productbased organization (PBO) and functional-based organization (FBO). For a PBO, it is shown that efficiency is independent of whether the firm or managers are liable for environmental damages; in a FBO it is optimal either to hold the firm liable for environmental damages or, equivalently, to only hold the environmental managers liable for damages. It is also shown that the two organizational structures are equally efficient when there is no correlation between environmental damages from products and no spillover between managerial effort across products or functions. Numerical results further reveal that beneficial spillovers between functions for the same product favours a PBO over a FBO; beneficial spillovers across functions favours a FBO.
\end{abstract}

Keywords Contracts · Multi-task · Principal-agent · Environmental compliance · Environmental liability · Governance framework

We are grateful for constructive comments from three anonymous referees as well as seminar participants at the University of Western Australia. Any errors are our own.

Frans P. de Vries

f.p.devries@stir.ac.uk

1 Federal Planning Bureau, Brussels, Belgium

2 Division of Economics, University of Stirling Management School, Stirling, Scotland FK9 4LA, UK

3 School of Agriculture and Environment, University of Western Australia, Perth, Australia 


\section{Introduction}

The interplay between compliance and environmental liability are fundamental to balancing production and environmental objectives within corporations. A case in point is Volkswagen's emissions scandal. Elson et al. (2015) show how Volkswagen's corporate governance and organizational structure led to management practices which were non-compliant with environmental regulation, despite the corporation stating well-defined and transparent environmental targets. This case illustrates that the "compliance function" (Miller 2018) within Volkswagen did not operate effectively within the firm as an internal control mechanism. With the potential for conflicting organizational objectives around profitability and environmental performance, there is renewed interest in corporate behaviour towards regulatory compliance and the legal implications for managers and the corporation of environmental non-compliance (Langevoort 2018).

The Volkswagen scandal demonstrates that production and environmental decisions are not necessarily aligned to one another. Empirical studies analysing the relationship between corporate governance structures and environmental performance have, however, revealed a more positive relationship. For instance, Berrone and Gomez-Mejia (2009) find that financial rewards to senior managers are positively related to corporate environmental performance. The authors contend that effective environmental governance structures support and reinforce this linkage. Martin et al. (2012) report a case study showing that climate-oriented management practices are more likely to be adopted by corporations where decisions are taken by a designated environmental (or energy) manager. Pro-environmental management practices, in turn, tend to positively affect energy efficiency and productivity, which is conducive to meeting environmental objectives and to (potentially) avoiding regulatory non-compliance.

Walls et al. (2012) show that the interdependency between environmental performance and a corporation's organizational structure is multi-dimensional, and identify the need for additional theoretical work to analyse some of the core dependencies. This is what our paper intends to do. In particular, we contribute to the literature by taking an economic-organizational design perspective. The focus of our paper is on how to govern and organise production and environment-related decisions at the corporate level in a context of environmental liability. Through such a lens, the specific question that arises is how to allocate environmental liability within the boundaries of a corporation to maximize expected profit. We address this question by examining the interlinkage between environmental liability and a corporation's organizational structure.

To investigate this interdependency, we employ a multi-task principal-agent (MTPA) framework, which serves as a natural way to study the interaction between incentives and behaviour at the corporate and managerial levels. We adopt and modify the model developed by Besanko et al. (2005), which distinguishes between a 
product-based organization (PBO) and a functional-based organization (FBO). A FBO consists of functional divisions, such as production, research and development, marketing, finance, human resources, and environmental protection, each division covering all products. A PBO is organized into product lines, where each product manager is in charge of all functional areas for the product under her control. In what follows, we assume that a FBO has a two-divisional structure: one division responsible for the production ${ }^{1}$ of all final goods produced by the firm and another division responsible for environmental protection of all products. Both divisions, however, affect the level of gross profits and the level of environmental damage.

We show that the choice of organizational structure has implications for the allocation of liability between individual managers and the corporation. For riskaverse managers, our first result shows that the allocation of liability between the firm and manager does not matter for efficiency in a PBO. This neutrality result for the allocation of liability in a PBO is an extension of the neutrality propositions by Kornhauser (1982) and Sykes (1984). This result is also in line with Coase's (1960) theorem, in the sense that in a world without transaction costs the initial allocation of property rights does not affect efficiency. Arlen and MacLeod (2005) have confirmed this in an applied analysis of care organizations. Our second result indicates that the neutrality proposition does not necessarily hold in a FBO, implying that the allocation of liability does matter for a FBO. More specifically, in case of a FBO it is optimal either to hold the firm liable for environmental damages or to make the environmental function manager entirely liable.

The relevant literature in the environmental domain using a MTPA framework goes back to Gabel and Sinclair-Desgagné (1993), who analyze the effect of monetary incentives on environmental risk-reducing activities within corporations. The emphasis of their analysis is twofold. First, they explicitly take into account that there are objective upper bounds to the amount of effort that can be undertaken by an individual agent. Second, they analyze how the accuracy of technology, used to measure effort, affects the optimal incentive schemes. We extend Gabel and Sinclair-Desgagné (1993) in two ways. First, we analyze the effects of environmental penalties on the organizational structure. Second, instead of incorporating the incentives exogenously into the model, we endogenously determine the incentives for environmental protection from the corporation's profit-maximizing behaviour and assess how these incentives affect its functioning through the organizational structure. Sinclair-Desgagné and Gabel (1997) employ a principal-agent model to analyse the use of internal audits as a way to incentivize the management of environmental resources within the corporate hierarchy.

A related strand of literature that use MTPA models assesses the relative efficiency of different penalty schemes, including whether corporations or individual managers should be held liable to civil or criminal charges. Seminal contributions in this tradition (see Kraakman 2000) are Kornhauser (1982) and Sykes (1984, 1988), whereas Segerson and Tietenberg (1992) offer a first application to the specific problem of environmental enforcement. MTPA has also been applied to job design issues

\footnotetext{
${ }^{1}$ Here we relate to production in the broadest sense, including supporting activities mentioned above such as marketing and human resources.
} 
(Holmstrom and Milgrom 1991) and to the study of incentives and allocation for teaching and research in universities (Gautier and Wauthy 2007). Corts (2006) offers a more fundamental study examining the interplay between tasks and asset ownership. Further, the literature on vicarious liability (Kornhauser 1982) traditionally compares the efficiency of imposing civil liability on the principal (here the firm) rather than on the agent (here the manager). Segerson and Tietenberg (1992) also consider the possibility of criminal sanctions imposed on managers, but this topic is beyond the scope of this paper. To foster transparency and clarity throughout the analysis, we concentrate here solely on the incentive structure and exclude the option of criminal sanctions.

\section{The model}

We adopt the model developed by Besanko et al. (2005), but make it specific for our purpose by embedding environmental protection into it. Consider a firm that consists of a risk-neutral owner and two risk-averse managers. The firm sells two products, indexed $i=1,2$. There are two functional areas indexed $f=e, p$ : environmental protection $(e)$ and production $(p)$. Production should be seen here as a proxy for all non-environmentally-related functional areas. Further, for each product $i$, denote $e_{i}$ and $p_{i}$ as the effort levels managers expend on the environmental and production functions, respectively. In a $\mathrm{FBO}, e_{i}$ is the effort of the environmental manager to reduce the emissions of product $i$; in a $\mathrm{PBO}, e_{i}$ is the effort of the manager that is responsible for product line $i$ to reduce the emissions associated with product $i$. A similar intuition applies to $p_{i}$. That is, whereas it expresses the effort of the production manager to manufacture product $i$ in a FBO, in a $\mathrm{PBO} p_{i}$ represents the effort of the manager that is responsible for product line $i$ to manufacture the product. The effort levels are endogenous and cannot be verified by outside parties, hence cannot form the basis of enforceable contracts.

Let $z_{i}^{T}=\left[p_{i}, e_{i}\right]$ (with $\left.i=1,2\right)$ and $v_{f}^{T}=\left[f_{1}, f_{2}\right]$ (with $f=e, p$ ) denote the managers' effort vectors in a PBO and FBO, respectively. It is assumed that the disutility of effort for a divisional manager in a PBO is given by $C_{i}\left(z_{i}\right)=\frac{1}{2} z_{i}^{T} C_{i} z_{i}(i=1,2)$; in case of a FBO, the disutility of effort is $C_{f}\left(v_{f}\right)=\frac{1}{2} v_{f}^{T} C_{f} v_{f}(f=e, p)$, where $C_{f} \equiv C_{i} \equiv\left[\begin{array}{ll}1 & \delta \\ \delta & 1\end{array}\right]$ and $\delta \in[0,1)$. The latter term reflects a manager's "diseconomies of span" when she has to split time and attention between different tasks (Besanko et al. 2005). This means that the product manager decides how to allocate effort between the two functions for their product, while the functional manager decides how to allocate effort between the two products for their function.

Gross profits (before wages and environmental penalties) for product $i$ are considered to be deterministic and linear:

$$
\pi_{i}\left(p_{i}, p_{j}, e_{i}, e_{j}\right)=\phi_{i} p_{i}+\eta_{i} e_{i}+s p_{i j} p_{j}+s e_{i j} e_{j} \quad i=1,2 \quad i \neq j .
$$

We assume that gross profits proportionally increase with production effort, i.e., $\phi_{i}>0$. The effect of environmental effort, $\eta_{i}$, on profit may be negative or positive. On the one hand, it could be negative if environmental effort increases production 
costs. On the other hand, as mentioned in the introduction, environmental effort can lead to energy-savings and improved energy efficiency and productivity. We also make no prior assumptions with respect to the sign of the spillover effects $s p_{i j}$ and $s e_{i j}$. For instance, it is possible that spillover effects capture the idea that production and environmental effort for one product can often increase the profitability of the the firm's other products (Besanko et al. 2005).

The environmental damage, $D_{i}$, from manufacturing product $i$ is given by:

$$
D_{i}\left(p_{i}, p_{j}, e_{i}, e_{j}\right)=d_{i} p_{i}+b_{i} e_{i}+s d_{i j} p_{j}+s b_{i j} e_{j}, \quad i=1,2 \quad i \neq j,
$$

where $d_{i}>0$ and $b_{i}<0$. As with profit, we make no prior assumptions with respect to the sign of the spillover effects $s d_{i j}$ and $s b_{i j}$. Equations (1) and (2) are based on the assumption that the link between effort on the one hand, and profit and environmental damage on the other hand, is independent of the firm's organizational structure. That is, a vector of effort allocations gives the same (gross) profit or environmental damage, regardless of the organizational structure. This allows us to isolate how the organizational structure affects the cost of effort to managers and the corresponding risk they face.

Suppose that the environmental regulator observes the following verifiable signal of product-related environmental quality:

$$
\tilde{D}_{i}=D_{i}+\tilde{\varepsilon}_{i}, \quad i=1,2,
$$

where the measurement error $\tilde{\varepsilon}_{i}$ has zero mean and $\left(\tilde{\varepsilon}_{1}, \tilde{\varepsilon}_{2}\right)$ follows a bivariate normal distribution with covariance matrix:

$$
\Omega_{D}=\left(\begin{array}{cc}
\sigma_{D}^{2} & r \sigma_{D}^{2} \\
r \sigma_{D}^{2} & \sigma_{D}^{2}
\end{array}\right) .
$$

Here $\sigma_{D}^{2}$ is the variance of measured environmental quality and $r \in[-1,1]$ is the correlation between the environmental damage signals from the products. The two identifiable signals of environmental performance, generated by this formulation, is applicable if products are manufactured in different locations or emit different pollutants. The term $r$ is the correlation between the noise in the measurement of signals for environmental damage, possibly because the signals are measured by the same type of equipment or by the same inspectors. ${ }^{2}$ Following Besanko et al. (2005), we further assume that it is impossible to identify the contributions of the functional areas to the products.

Holmstrom (1979) shows that incentive schemes within the firm should account for all signals that reduce the error in measuring the agent's effort. Our model includes four measures of management performance: two related to product profits $\left(\pi_{1}\right.$ and $\left.\pi_{2}\right)$ and two related to observed environmental performance $\left(\tilde{D}_{1}\right.$ and $\left.\tilde{D}_{2}\right)$. Following Holmstrom and Milgrom (1987), we restrict compensation packages to be linear

\footnotetext{
${ }^{2}$ If the two products are produced at the same location and emit the same pollutants, then the environmental regulator can only observe aggregate environmental damages $\tilde{D}_{\text {agg }}=\sum_{i=1,2} D_{i}+\tilde{\varepsilon}$. This corresponds to a nonpoint source pollution case where the exact source of damages is unclear. Here we restrict attention to point source pollution.
} 
functions of these variables. The incentive schemes are further limited to a subset of these variables. Thus, compensation of product managers is only linked to the performance in relation to their product; compensating functional managers is only linked to performance in their own function. In other words, the responsibilities of each manager correspond to the vector of performance signals the firm holds her responsible for.

If the contributions of individual products to pollution can be observed, and a share $1-\theta$ of liability is imposed on the manager by the firm in response to a penalty $\tilde{D}_{i}$ imposed on the firm by the regulator, then total wages, $\tilde{W}_{i}$, received by the manager of product division $i$ in a PBO are:

$$
\tilde{W}_{i}=a_{i 0}+\left[\pi_{i} ; \tilde{D}_{i}\right] a_{i}-(1-\theta) \tilde{D}_{i} \quad i=1,2,
$$

where $a_{i 0}$ is a constant, $a_{i}^{T} \equiv\left[a_{\pi_{i}}, a_{D_{i}}\right]$ is the payment schedule for a product division, and $(1-\theta) \tilde{D}_{i}$ is the penalty share imposed by the firm on the manager. If the firm is a FBO, payments are:

$$
\begin{aligned}
& \tilde{W}_{p}=\alpha_{p 0}+\pi^{T} \alpha_{p}-\psi_{p}(1-\theta)\left(\tilde{D}_{1}+\tilde{D}_{2}\right) \\
& \tilde{W}_{e}=\alpha_{e 0}+\tilde{D}^{T} \alpha_{e}-\psi_{e}(1-\theta)\left(\tilde{D}_{1}+\tilde{D}_{2}\right),
\end{aligned}
$$

where $\alpha_{e 0}$ and $\alpha_{p 0}$ are constants; $\alpha_{e}^{T} \equiv\left[\alpha_{D_{1}}, \alpha_{D_{2}}\right]$ and $\alpha_{p}^{T} \equiv\left[\alpha_{\pi_{1}}, \alpha_{\pi_{2}}\right]$ are the payment schedules for the environmental division and production division, respectively; $\pi^{T} \equiv\left[\pi_{1}, \pi_{2}\right]$ and $\tilde{D}^{T} \equiv\left[\tilde{D}_{1}, \tilde{D}_{2}\right]$; and $\psi_{f}(1-\theta)\left(\tilde{D}_{1}+\tilde{D}_{2}\right)$ is the penalty schedule imposed by the firm on a manager in a functional organization, with $\psi_{e}+\psi_{p}=1$.

A manager's expected utility in a PBO can be written as:

$$
E U_{i} \equiv E\left(\tilde{W}_{i}\right)-\rho \frac{\operatorname{Var}\left(\tilde{W}_{i}\right)}{2}-C_{i}\left(z_{i}\right) \quad i=1,2,
$$

and as:

$$
E U_{f} \equiv E\left(\tilde{W}_{f}\right)-\rho \frac{\operatorname{Var}_{f}\left(\tilde{W}_{f}\right)}{2}-C_{f}\left(v_{f}\right) \quad f=e, p,
$$

for a manager in a FBO. The term $\rho>0$ reflects managers' Arrow-Pratt measure of absolute risk aversion, which is assumed to be the same across both managers. Taking into account that the only non-deterministic component of the manager's utility function is the environmental damage signal, the variances of the compensation schemes are:

$$
\begin{gathered}
\operatorname{Var}\left(\tilde{W}_{i}\right)=\sigma_{D}^{2}\left(a_{i}-\Theta\right)^{T} M\left(a_{i}-\Theta\right) \quad i=1,2 \\
\operatorname{Var}_{e}\left(\tilde{W}_{e}\right)=\alpha_{e}^{T} \Omega_{D} \alpha_{e}+2(1-\theta)^{2}(1+r) \psi_{e}^{2} \sigma_{D}^{2}-2(1+r)(1-\theta) \psi_{e} \sigma_{D}^{2} \alpha_{e}^{T} u
\end{gathered}
$$




$$
\operatorname{Var}_{p}\left(\tilde{W}_{p}\right)=2(1-\theta)^{2}(1+r) \psi_{p}^{2} \sigma_{D}^{2}
$$

with $M \equiv\left[\begin{array}{ll}0 & 0 \\ 0 & 1\end{array}\right], \Theta^{T} \equiv[0,1-\theta]$ and $u^{T} \equiv[1,1]$.

Manager $i$ 's expected utility expressed in (7) can now explicitly be specified for the two distinguished organizational structures. Substituting (5) into (7), the expected utility for managers in a PBO reads as expected wages minus the expected liability payments, minus the risk premium, minus the disutility of effort:

$$
E U_{i}=a_{i 0}+\left[\pi_{i}\left(z_{i}, z_{j}\right) ; D_{i}\left(z_{i}, z_{j}\right)\right]^{T} a_{i}-(1-\theta) D_{i}\left(z_{i}, z_{j}\right)-\rho \frac{\operatorname{Var}\left(\tilde{W}_{i}\right)}{2}-C_{i}\left(z_{i}\right) \quad i \neq j,
$$

with $\operatorname{Var}\left(\tilde{W}_{i}\right)$ given in (9a). The expected utility of managers in a FBO can be derived by substituting (6a) and (6b) into (8), which yield, respectively:

$$
\begin{aligned}
& E U_{e}=\alpha_{e 0}+\left[D_{1}\left(v_{e}, v_{P}\right) ; D_{2}\left(v_{e}, v_{p}\right)\right]^{T} \alpha_{e}-\psi_{e}(1-\theta) \sum_{i \in 1,2} D_{i}\left(v_{e}, v_{p}\right)-\rho \frac{\operatorname{Var}\left(\tilde{W}_{e}\right)}{2}-C_{e}\left(v_{e}\right) \\
& E U_{p}=\alpha_{p 0}+\left[\pi_{1}\left(v_{e}, v_{p}\right) ; \pi_{2}\left(v_{e}, v_{p}\right)\right]^{T} \alpha_{p}-\psi_{p}(1-\theta) \sum_{i \in 1,2} D_{i}\left(v_{e}, v_{p}\right)-\rho \frac{\operatorname{Var}\left(\tilde{W}_{p}\right)}{2}-C_{p}\left(v_{p}\right),
\end{aligned}
$$

with $\operatorname{Var}\left(\tilde{W}_{e}\right)$ and $\operatorname{Var}\left(\tilde{W}_{p}\right)$ defined by (9b) and (9c), respectively. Following Besanko et al. (2005), we normalize the managers' reservation utility to zero (i.e., $E U_{i}=0$ ). The intercept of the compensation schemes can then be used to satisfy the participation constraint. In that case, the owner's objective is to maximize total surplus (i.e., profit minus the risk premium, minus the disutility of effort, minus the penalties imposed on the managers) subject to the IC constraints.

In case of a PBO the IC constraints are:

$$
\left[Q_{i} ; S_{i}\right] a_{i}-(1-\theta) S_{i}=C_{i} z_{i}, \quad i=1,2,
$$

where $Q_{i}^{T}=\left[\phi_{i}, \eta_{i}\right]$ and $S_{i}^{T}=\left[d_{i}, b_{i}\right]$. To facilitate and simplify the analysis of the optimal solution in the next section, the IC constraint can also be written more succinctly as $\left[Q_{i} ; S_{i}\right]\left[a_{i}-\Theta\right]=C_{i} z_{i}$. Finally, under a FBO the IC constraints for the functional areas $f=e, p$ are, respectively:

$$
\begin{aligned}
T_{e} \alpha_{e}-(1-\theta) \psi_{e} T_{e} u & =C_{e} v_{e} \\
R_{p} \alpha_{p}-(1-\theta) \psi_{p} T_{p} u & =C_{p} v_{p}
\end{aligned}
$$


with $T_{e}=\left[\begin{array}{cc}b_{1} & s b_{21} \\ s b_{12} & b_{2}\end{array}\right], T_{p}=\left[\begin{array}{cc}d_{1} & s d_{21} \\ s d_{12} & d_{2}\end{array}\right]$ and $R_{p}=\left[\begin{array}{cc}\phi_{1} & s p_{21} \\ s p_{12} & \phi_{2}\end{array}\right]$. Equation (13a) is the IC constraint related to the environmental manager, which reflects the transfer payment and liability. For this manager, matrix $T_{e}$ appears in the term related to the transfer payment and the term related to liability. In contrast, (13b) shows that the product manager gets paid on the basis of profit (through the $R_{p}$ matrix), but they also account for their share of the extra environmental cost, as reflected by the $T_{p}$ matrix.

The solutions for the organizational structures can be compared with the perfect information (i.e., "first-best") solution where the risk neutral firm owner pays the managers directly for their observed level of effort. The firm's owner absorbs the variation in the environmental penalty and assumes the liability:

$$
\operatorname{Max} \sum_{i=1,2 ; i \neq j}\left(\pi_{i}\left(p_{i}, p_{j}, e_{i}, e_{j}\right)-D_{i}\left(p_{i}, p_{j}, e_{i}, e_{j}\right)-\frac{z_{i}^{T} C_{i} z_{i}}{2}\right) .
$$

The optimal (internal) solution is found where marginal net profit with respect to the vector of all effort equates with the marginal cost of effort. The details and derivation of this solution is given in the Appendix and used as a benchmark for the numerical example in Section 3.4.

This completes the full description of the model. We are now in a position to examine how the various conditions apply to the two organizational regimes, to which we turn next.

\section{Analysis and comparison of organizational structures}

We will analyze and compare the two organizational structures under the assumption of risk-averse managers by following the first-order approach in solving the MTPA problem (see Sinclair-Desgagné 1994). The analysis is further based on the assumption that the firm and managers are not able to avoid liability by strategically declaring bankruptcy.

A total of five results are derived analytically. This is complemented by a numerical exercise, which enables us to examine the relative performance of a PBO and FBO under different parameter sets. It also allows us to assess model sensitivity. All the derivations and proofs are in the Appendix and are based on representing both organizational structures using common matrix notation.

On the basis of the analytical and numerical analyses, it emerges that extending liability to managers plays a minor role in the efficiency of the firm. The reason for this is that the firm has to compensate managers for the extra liability, and this compensation fully adjusts for additional liability. Based on numerical analyses over a range of parameter values, liability has no effect on effort in a FBO, but does change the firm's profitability when the share of environmental damage is not fully assigned to the environmental manager. 
The second insight from our modelling exercise is in terms of the choice of organizational structure. In simple terms, if there are beneficial effects within a function, then a FBO is favoured. This is because a manager internalises the beneficial spillovers between functions for a product. In contrast, if beneficial spillovers are across functions for a product, this favours a PBO. This contrasting finding provides an insight into the potential role of "green" technologies in production. For instance, in some firms energy savings can increase profits, whilst in other settings pollution control activities and expenditures can reduce profitability.

Before providing some more detail underlying the full list of results, we list them systematically below.

Result 1 The performance of a PBO is liability-neutral.

Result 2 In a FBO, it is always optimal to allocate all environmental liability to the environmental manager.

Result 3 In a FBO, profit varies with liability if an arbitrary share of environmental damage is allocated to the environmental manager, implying non-neutral liability. This is a corollary of Result 2.

Result 4 The PBO and FBO are equivalent in terms of effort and social welfare if there are no spillover externalities and the correlation between measurements of environmental damage from products is zero.

Result 5 Beneficial spillovers within managers' domain increase the effort and thus social welfare for that organizational structure over the other.

\subsection{Result 1: PBO neutrality}

In a $\mathrm{PBO}$, the risk-neutral owner of the firm maximizes gross profits less compensation and the share of the fine paid by the firm:

$$
\Pi^{\mathrm{PBO}}=\sum_{i=1,2 ; i \neq j}\left[u^{T} P_{i} z_{i}-\left(a_{i 0}+\left(\pi_{i} ; \tilde{D}_{i}\right) a_{i}\right)-\theta \tilde{D}_{i}\right],
$$

where $P_{i}=\left[\begin{array}{cc}\phi_{i} & b_{i} \\ s p_{j i} & s b_{j i}\end{array}\right]$. If the individual rationality constraint is binding, using (10) allows us to rewrite the objective function in matrix form

$$
\Pi^{\mathrm{PBO}}=\sum_{i=1,2 ; i \neq j}\left[u^{T} P z_{i}-\rho \frac{\sigma_{D}^{2}\left[\left(a_{i}^{T}-\Theta\right) M\left(a_{i}-\Theta\right)\right]}{2}-\frac{z_{i}^{T} C_{i} z_{i}}{2}\right]-\tilde{D} u
$$

subject to the IC constraints 


$$
C_{i} z_{i}=\left[Q_{i} ; S_{i}\right] a_{i}-(1-\theta) S_{i} \equiv\left[Q_{i} ; S_{i}\right]\left[a_{i}-\Theta\right] \quad i=1,2
$$

Solving for $z_{i}$ gives:

$$
z_{i}=\Psi_{i}\left(a_{i}-\Theta\right)
$$

where $\Psi_{i}=C_{i}^{-1}\left[Q_{i} ; S_{i}\right]$. Substituting (17) into (16) and taking the derivative with respect to $a_{i}$ yields the optimal value for the compensation payments:

$$
a_{i}^{T}=\left(\Psi_{i}^{T} C_{i} \Psi_{i}+M \rho \sigma_{D}^{2}\right)^{-1} u^{T}\left(P_{i}\right) \Psi_{i} u+\Theta^{T} .
$$

Substituting this expression into the IC constraint (17) it becomes immediately evident that profit is independent of the liability imposed upon managers, since the liability term $\Theta$ cancels out. The main intuition is that the individual rationality constraint ensures that the transfer payment for environmental performance is directly adjusted for liability.

\subsection{Results 2-4: FBO allocation of liability, neutrality and equivalence}

Result 2, which indicates that it is always optimal to allocate all environmental liability to the envrionmental manager, is a direct consequence of the variance equations (9b) and (9c). The variance of the product manager is independent of the transfer payment. Allocating risk to the product manager, therefore, increases wages without increasing effort, hence is a deadweight loss. On that basis we can restrict attention to schemes where $\psi_{p}=0$ (and, correspondingly, $\psi_{e}=1$, since $\left.\psi_{e}+\psi_{p}=1\right)$.

The firm's objective function for a FBO structure is:

$$
\Pi^{\mathrm{FBO}}=\left[u^{T} T_{p} v_{p}-\left(\alpha_{p 0}+\pi^{T} \alpha_{p}\right)\right]+\left[u^{T} T_{e} v_{e}-\left(\alpha_{e 0}+\tilde{D}^{T} \alpha_{e}\right)\right]-\theta \tilde{D} u .
$$

This profit function is maximized subject to the IC constraints (13a) and (13b) (again with $\psi_{e}=1$ ). Solving this constrained optimization problem leads to Result 3 and 4 (see the Appendix for derivations and proofs).

\subsection{Result 5: beneficial spillovers}

Beneficial spillovers are defined to relate to parameters $\eta_{i}, s p_{i j}$, and $s e_{i j}$ in the profit function, and $s d_{i j}$ and $s b_{i j}$ in the damage function. The intuition is that if a beneficial spillover occurs within a manager's domain of responsibility, they account for that benefit and optimise effort accordingly. For instance, $\eta_{i}$ is the effect of environmental effort on profit within a PBO manager's domain. The more beneficial environmental effort $e_{i}$ is to the profit of product $\pi_{i}$, the higher the effort is of a PBO compared to a FBO. An example of a beneficial spillover within a manager's domain in case of a FBO is parameter $s b_{i j}$. This means that environmental effort for one product reduces damage by the other product. If this parameter is 
beneficial (i.e., negative in this case), it implies that a FBO involves a higher level of optimal effort than a PBO.

\subsection{Comparison of organizational structures: a numerical exercise}

Further to the main analytical results derived above, we present a numerical example to assess the relative performance of a PBO and FBO under alternative parameter sets. This further explores Result 5 by relaxing the restrictive assumptions about parameters in the profit and damage function. The problem has a structure that allows us to identify sets of parameters that ensure the firm is viable. This means that for both a PBO and FBO profit is postive for some $p_{i}, e_{i} \in \mathbb{R}^{+}$. For a firm to incentivize any production effort from a risk-neutral manager, the marginal net profit has to be non-negative, i.e., $\phi_{i}+s p_{i j}-d_{i}-s d_{i j}-p_{i} \geq 0$. For the firm to incentivize environmental effort it implies that $-b_{i}-s b_{i j}+\eta_{i}+s e_{i j}-e_{i} \geq 0$. Note that the last terms in these expressions ( $p_{i}$ and $e_{i}$, respectively) denote the marginal cost of effort. The following assumptions allow us to construct an internal solution:

1. The two products have identical profit functions, environmental damage functions and behavioural parameters;

2. Production (environmental) effort strictly increases (decreases) environmental damage (i.e., $d_{1}, d_{2}>0$ and $b_{1}, b_{2}<0$, respectively);

3. The baseline solution is where all spillover effects are zero $\left(s p_{12}=s p_{21}=s e_{12}=s e_{21}=0\right)$ and environmental effort has no effect on profit $\left(\eta_{1}=\eta_{2}=0\right)$, the correlation between sources of environmental damage is zero, and the allocation of a share of environmental damage to the product division is zero;

4. The parameters for product effort are normalised to $\phi_{1}=\phi_{2}=1$.

5. Risk aversion is set at $\rho=0.03$ and is identical for both managers and the variance equal to $\sigma_{D}^{2}=2$.

For the parameters in Table 1, a firm with risk-neutral managers would target effort defined by the optimal internal solution such that $p_{1}=p_{2}=1-0.3=0.7$ and environmental effort $e_{1}=e_{2}=0.4$. This result can be modified to account for risk aversion related to random environmental damage by adding a risk premium function, $r p\left(e_{i}\right)=\frac{\rho \operatorname{Var}\left(e_{i}\right)}{2}$, which has the effect of reducing the environmental effort. For an internal solution: $-b_{i}-s b_{i j}+\eta_{i}+s e_{i j}-r p^{\prime}\left(e_{i}\right)-e_{i}=0$ and $r p^{\prime}\left(e_{i}\right)>0$.

Table 1 contains all assessed parameter sets as well as the corresponding results. The baseline case (a) is where the PBO and FBO are equivalent, and confirms the analytical results as derived earlier. The parameters are then systematically varied to derive comparative statics results. Comparing parameter sets (b) and (c) with the baseline (a) shows that a PBO is more (less) efficient than a FBO when the correlation between product-line environmental damages is positive (negative). This result is explained by the fact that a positive correlation in the damage from two products 


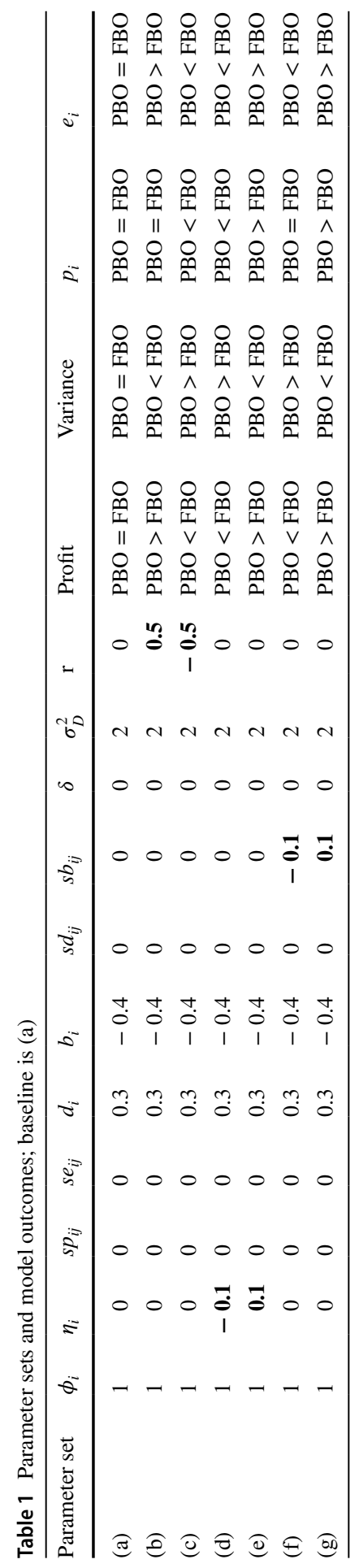


affects the variance of measured environmental quality. This increases wages in a FBO; however, it has no effect on the variance of a PBO, as it is independent of the correlation coefficient [cf. Eqs. (9a)-(9c)].

\section{Conclusion}

This paper employs a multi-task principal-agent model to examine how a firm's organizational structure and liability rules for environmental damages affect the incentive schemes offered to managers. Two organizational structures are compared: a product-based organization (PBO) and a functional-based organization (FBO). In a PBO managers are responsible for all functions of a single product; in a FBO managers are responsible for functions across all products. For a PBO it is shown that efficiency is independent of whether the corporation or managers are held liable for environmental damages. In a FBO it is optimal either to hold the corporation liable for environmental damages or to allocate all the liability to the manager responsible for the environmental function. Imposing liability on the production manager in a FBO increases risk without affecting incentives and increasing production or environmental effort.

If the marginal effects of effort on gross profits and environmental damages are constant, then it is possible to compare the effort levels under the two organizational structures. Analytical and numerical results indicate that the preferred organizational structure for society and the corporation is one where beneficial spillovers arise across the managerial domain of responsibility. For instance, a FBO is preferred over a PBO if beneficial spillovers (i.e., ones that increase profit or reduce environmental damages) are present across environmental effort related to different products.

\section{Appendix}

\section{Assumptions}

(A1) All managers have the same risk aversion parameter.

(A2) The share of environmental damage in a FBO is always imposed on the environmental manager (i.e., $\psi_{e}=1$ ).

\section{Matrix specification for organizational comparison}

Here we restate the $\mathrm{PBO}$ and FBO results using a common format, which allows for a general comparison of the organizational structures. The coefficients of the (linear) profit and damage functions can be represented in a single matrix as follows 


$$
B=\left[\begin{array}{llll}
\frac{\partial \pi_{1}}{\partial p_{1}} & \frac{\partial \pi_{1}}{\partial p_{2}} & \frac{\partial \pi_{1}}{\partial e_{1}} & \frac{\partial \pi_{1}}{\partial e_{2}} \\
\frac{\partial \pi_{2}}{\partial p_{1}} & \frac{\partial \pi_{2}}{\partial p_{2}} & \frac{\partial \pi_{2}}{\partial e_{1}} & \frac{\partial \pi_{2}}{\partial e_{2}} \\
\frac{\partial D_{1}}{\partial p_{1}} & \frac{\partial D_{1}}{\partial p_{2}} & \frac{\partial D_{1}}{\partial e_{1}} & \frac{\partial D_{1}}{\partial e_{2}} \\
\frac{\partial D_{2}}{\partial p_{1}} & \frac{\partial D_{2}}{\partial p_{2}} & \frac{\partial D_{2}}{\partial e_{1}} & \frac{\partial D_{2}}{\partial e_{2}}
\end{array}\right]=\left[\begin{array}{cccc}
\phi_{1} & s p_{12} & \eta_{1} & s e_{12} \\
s p_{21} & \phi_{2} & s e_{21} & \eta_{2} \\
d_{1} & s d_{12} & b_{1} & s b_{12} \\
s d_{21} & d_{2} & s b_{21} & b_{2}
\end{array}\right] .
$$

The variance-covariance matrix is extended to

$$
\Omega^{A}=\left[\begin{array}{cccc}
0 & 0 & 0 & 0 \\
0 & 0 & 0 & 0 \\
0 & 0 & \sigma_{D}^{2} & r \sigma_{D}^{2} \\
0 & 0 & r \sigma_{D}^{2} & \sigma_{D}^{2}
\end{array}\right] .
$$

Given our aforementioned assumption of $\psi_{e}=1$, for both the PBO and FBO the extended liability vector is given by

$$
\left(\Theta^{A}\right)^{T}=[0,0,(1-\theta),(1-\theta)] .
$$

The total variance for a PBO is

$$
\operatorname{Var}_{k}\left(\alpha_{k}, \Theta^{A}\right)=\sigma_{D}^{2}\left(\alpha_{k}-\Theta^{A}\right)^{T} M^{A}\left(\alpha_{k}-\Theta^{A}\right) \quad k=\mathrm{PBO}
$$

where $M^{A}$ is

$$
M^{A}=\left[\begin{array}{llll}
0 & 0 & 0 & 0 \\
0 & 0 & 0 & 0 \\
0 & 0 & 1 & 0 \\
0 & 0 & 0 & 1
\end{array}\right]
$$

The total variance for a FBO is

$$
\operatorname{Var}_{k}\left(\alpha_{k}, \Theta^{A}\right)=\left(\alpha_{k}-\Theta^{A}\right)^{T} \Omega^{A}\left(\alpha_{k}-\Theta^{A}\right) \quad k=\mathrm{FBO}
$$

The firm's total effort cost for a given organizational structure is

$$
T C_{k}=\frac{z^{T} C_{k}^{A} z}{2} \quad k=\mathrm{PBO}, \mathrm{FBO}
$$

If $\delta=0$, the $C_{k}^{A}$ matrix is a $4 \times 4$ identity matrix; otherwise it reads as

$$
C_{\mathrm{PBO}}^{A}=\left[\begin{array}{llll}
1 & 0 & \delta & 0 \\
0 & 1 & 0 & \delta \\
\delta & 0 & 1 & 0 \\
0 & \delta & 0 & 1
\end{array}\right] C_{\mathrm{FBO}}^{A}=\left[\begin{array}{llll}
1 & \delta & 0 & 0 \\
\delta & 1 & 0 & 0 \\
0 & 0 & 1 & \delta \\
0 & 0 & \delta & 1
\end{array}\right] .
$$

Diseconomies of span penalise a PBO manager who divides her time between production and environmental effort. In case of a FBO it entails penalising allocating effort between products across the same function. The compensation vectors for the 
organizational types are: $\alpha_{\mathrm{PBO}}^{T}=\left[a_{1 \pi}, a_{2 \pi}, a_{1 D}, a_{2 D}\right]$ and $\alpha_{\mathrm{FBO}}^{T}=\left[\alpha_{1 \pi}, \alpha_{2 \pi}, \alpha_{1 D}, \alpha_{2 D}\right]$. The fixed payments to ensure participation are: $\alpha_{0, \mathrm{PBO}}^{T}=\left[a_{01}, a_{02}\right]$ and $\alpha_{0, \mathrm{FBO}}^{T}=\left[\alpha_{0 p}, \alpha_{0 e}\right]$.

The organizational structures are differentiated by the IC constraints. The PBO accounts for the direct effects of product and environmental effort, and the spillover effects within the product division. The FBO accounts for spillover effects across their functional area. In general, the IC constraint is given by the marginal condition:

$$
C_{k}^{A} z=B_{k}\left(\alpha_{k}-\Theta_{k}^{A}\right) \quad k=\mathrm{PBO}, \mathrm{FBO},
$$

where $B_{k}=I C_{k} \circ B^{T}$ and with o indicating element-wise matrix multiplication

$$
I C_{\mathrm{PBO}}=\left[\begin{array}{llll}
1 & 0 & 1 & 0 \\
0 & 1 & 0 & 1 \\
1 & 0 & 1 & 0 \\
0 & 1 & 0 & 1
\end{array}\right] I C_{\mathrm{FBO}}=\left[\begin{array}{llll}
1 & 1 & 0 & 0 \\
1 & 1 & 0 & 0 \\
0 & 0 & 1 & 1 \\
0 & 0 & 1 & 1
\end{array}\right] .
$$

This notation allows the PBO and FBO firms' objective function to be analysed using a common format. It is also useful to define the term $\Psi_{k}=\left(C_{k}^{A}\right)^{-1} B_{k}$. After the participation constraint has been substituted into the objective function one obtains

$$
\Pi^{k}=y^{T} B z-\rho \frac{\operatorname{Var}_{k}\left(\alpha_{k}, \Theta^{A}\right)}{2}-\frac{z^{T} C_{k}^{A} z}{2} \quad k=\mathrm{PBO}, \mathrm{FBO}
$$

\section{The optimal (first-best) solution}

$$
\Pi=y^{T} B z-\frac{z^{T} C_{k}^{A} z}{2} .
$$

Differentiating and solving for $z$ yields the following optimal level of effort

$$
z^{*}=\left(C_{k}^{A}\right)^{-1} B y
$$

The first-best solution provides the usual benchmark. It also allows a measure of the cost of inaccurate monitoring by the regulator.

\section{Result 1}

For a PBO, substituting into the objective function for $z_{k}=\Psi_{k}\left(\alpha_{k}-\Theta^{A}\right)$, the IC constraint gives:

$$
\Pi^{k}=y^{T} B \Psi_{k}\left(\alpha_{k}-\Theta_{k}\right)-\rho \frac{\sigma_{D}^{2}\left(\alpha_{k}-\Theta^{A}\right)^{T} M^{A}\left(\alpha_{k}-\Theta^{A}\right)}{2}-\frac{\left[\Psi_{k}\left(\alpha_{k}-\Theta^{A}\right)\right]^{T} C_{k}^{A}\left[\Psi_{k}\left(\alpha_{k}-\Theta^{A}\right)\right]}{2} .
$$

Taking the derivative with respect to $\alpha_{\mathrm{PBO}}$ and setting equal to zero yields: 


$$
\left(\alpha_{k}-\Theta^{A}\right)^{T}=y^{T} B \Psi_{k} \Xi_{k}^{-1} \quad k=\mathrm{PBO},
$$

where $\Xi_{k}=\rho \sigma_{D}^{2} M^{A}+\Psi_{k}^{T} C_{k}^{A} \Psi_{k}$. Substituting this into the objective function and the IC constraint, Result 1 follows directly as the level of effort and the level of profit is independent of liability. The optimal effort vector is derived from the IC constraint (20)

$$
z_{k}=\Psi_{k}\left(y^{T} B \Psi_{k} \Xi_{k}^{-1}\right)^{T} \quad k=\mathrm{PBO} .
$$

\section{Result 2: FBO neutrality when $\Psi_{e}=1$}

For a $\mathrm{FBO}$, the objective function is:

$$
\Pi^{k}=y^{T} B \Psi_{k}\left(\alpha_{k}-\Theta^{A}\right)-\rho \frac{\left(\alpha_{k}-\Theta^{A}\right)^{T} \Omega^{A}\left(\alpha_{k}-\Theta^{A}\right)}{2}-\frac{\left[\Psi_{k}\left(\alpha_{k}-\Theta^{A}\right)\right]^{T} C_{k}^{A} \Psi_{k}\left(\alpha_{k}-\Theta^{A}\right)}{2} .
$$

Taking the derivative with respect to $\alpha_{\mathrm{FBO}}$ and setting equal to zero yields:

$$
\left(\alpha_{k}-\Theta^{A}\right)^{T}=y^{T} B \Psi_{k} \Xi_{k}^{-1} \quad k=\mathrm{FBO},
$$

where $\Xi_{k}=\rho \Omega^{A}+\Psi_{k}^{T} C_{k}^{A} \Psi_{k}$. From this result it is clear that the level of effort and profit is independent of liability as from the IC constraint (20):

$$
z_{k}=\Psi_{k}\left(y^{T} B \Psi_{k} \Xi_{k}^{-1}\right)^{T} \quad k=\mathrm{FBO} .
$$

\section{Result 3: FBO when $\psi_{e}<1$ and $\psi_{e}+\psi_{p}=1$}

This result generalises the result for an FBO where the shares of environmental damage are allocated between the environmental and production functions. There are now two liability vectors: $\left(\Theta^{e}\right)^{T}=\left[0,0, \psi_{e}(1-\theta), \psi_{e}(1-\theta)\right]$ for the environmental manager and $\left(\Theta^{p}\right)^{T}=\left[0,0, \psi_{p}(1-\theta), \psi_{p}(1-\theta)\right]$ for the production manager. Note that $\Theta^{p}=\left(\Theta^{A}-\Theta^{e}\right)$, incorporates the constraint $\psi_{e}+\psi_{p}=1$. It has already been established that the share of environmental costs imposed on the production manager does not affect effort, as the variance for the production manager is constant.

For a FBO, the objective function, following the substitution of the participation constraint and IC constraint, reads

$$
\begin{aligned}
\Pi^{k}= & y^{T} B \Psi_{k}\left(\alpha_{k}-\Theta^{e}\right)-\rho \frac{\left[\left(\alpha_{k}-\Theta^{e}\right)^{T} \Omega^{A}\left(\alpha_{k}-\Theta^{e}\right)\right]}{2}-\rho \frac{\left[\left(\Theta^{p}\right)^{T} \Omega^{A} \Theta^{p}\right]}{2} \\
& -\frac{\left[\Psi_{k}\left(\alpha_{k}-\Theta^{e}\right)\right]^{T} C_{k}^{A} \Psi_{k}\left(\alpha_{k}-\Theta^{e}\right)}{2} \quad k=\mathrm{FBO}
\end{aligned}
$$


Taking the derivative of the objective function with respect to $\alpha_{\mathrm{FBO}}$ and setting equal to zero yields:

$$
\left(\alpha_{k}-\Theta^{e}\right)^{T}=y^{T} B \Psi_{k} \Xi_{k}^{-1},
$$

where $\Xi_{k}=\rho \Omega^{A}+\Psi_{k}^{T} C_{k}^{A} \Psi_{k}$. From this result it is clear that the level of effort and profit is independent of liability as from the IC constraint (20)

$$
z_{k}=\Psi_{k}\left(y^{T} B \Psi_{k} \Xi_{k}^{-1}\right)^{T} .
$$

The profitability of the firm depends on how the damage, and therefore the risk, is allocated. If the share of risk is optimised, we show that it is optimal in general for a FBO to allocate risk exclusively to the environmental function. This can be shown by taking the derivative of the objective function with respect to the vector $\Theta^{e}$, noting that $\Theta^{p}=\left(\Theta^{A}-\Theta^{e}\right)$. Following simplification, the derivative yields:

$$
\left(\Theta^{p}\right)^{T}=\frac{1}{\rho}\left(-\left(\alpha_{k}-\Theta^{e}\right)^{T} \Xi_{k}+y^{T} B \Psi_{k}\right)\left(\Omega^{A}\right)^{-1} .
$$

Substituting from (26) for $\left(\alpha_{k}-\Theta^{e}\right)^{T}$ then gives:

$$
\left(\Theta^{p}\right)^{T}=\frac{1}{\rho}\left(-y^{T} B \Psi_{k} \Xi_{k}^{-1} \Xi_{k}+y^{T} B \Psi_{k}\right)\left(\Omega^{A}\right)^{-1}=0,
$$

which indicates that it is always optimal to allocate liability entirely to the environmental manager as the optimal share of environmental damage allocated to the production manager is zero.

\section{Result 4}

This result applies to $\psi_{e}=1, r=0$ and restricted parameters. The matrix of coefficients is given by:

$$
B=\left[\begin{array}{llll}
\frac{\partial \pi_{1}}{\partial p_{1}} & \frac{\partial \pi_{1}}{\partial p_{2}} & \frac{\partial \pi_{1}}{\partial e_{1}} & \frac{\partial \pi_{1}}{\partial e_{2}} \\
\frac{\partial \pi_{2}}{\partial p_{1}} & \frac{\partial \pi_{2}}{\partial p_{2}} & \frac{\partial \pi_{2}}{\partial e_{1}} & \frac{\partial \pi_{2}}{\partial e_{2}} \\
\frac{\partial D_{1}}{\partial p_{1}} & \frac{\partial D_{1}}{\partial p_{2}} & \frac{\partial D_{1}}{\partial e_{1}} & \frac{\partial D_{1}}{\partial e_{2}} \\
\frac{\partial D_{2}}{\partial p_{1}} & \frac{\partial D_{2}}{\partial p_{2}} & \frac{\partial D_{2}}{\partial e_{1}} & \frac{\partial D_{2}}{\partial e_{2}}
\end{array}\right]=\left[\begin{array}{cccc}
\phi_{1} & 0 & 0 & 0 \\
0 & \phi_{2} & 0 & 0 \\
d_{1} & 0 & b_{1} & 0 \\
0 & d_{2} & 0 & b_{2}
\end{array}\right] .
$$

The equivalance proof between the organizational types requires showing that $z$ $\mathrm{PBO}=z_{\mathrm{FBO}}$ 


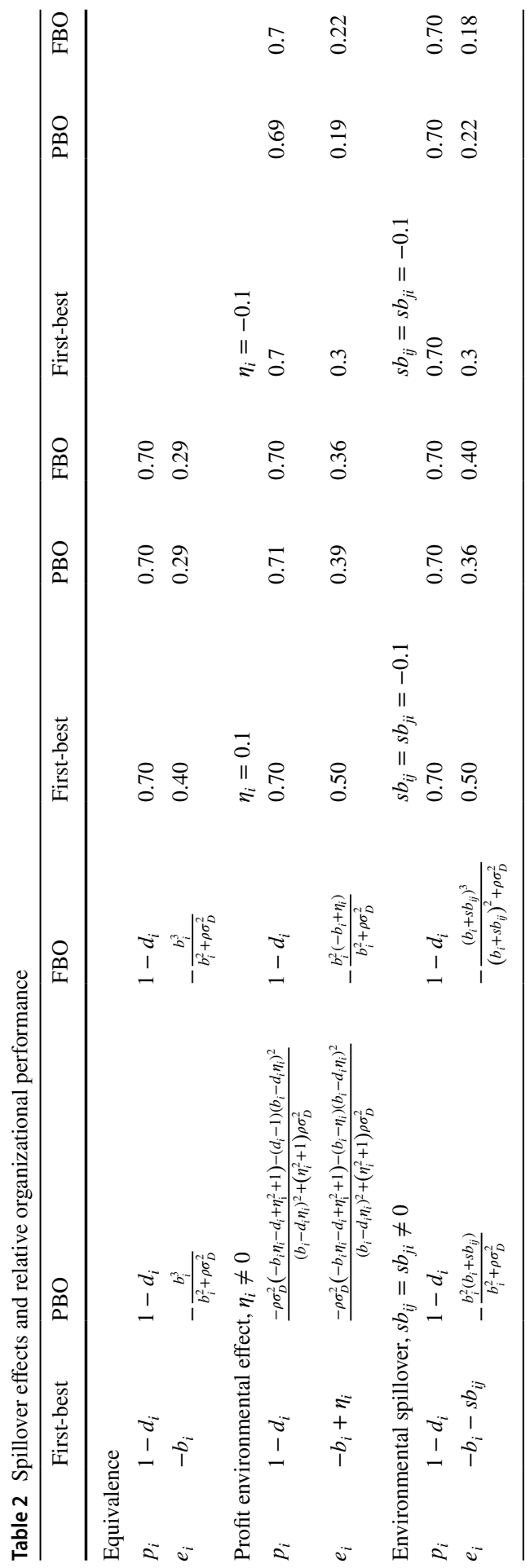




$$
z_{\mathrm{PBO}}=\left[\begin{array}{c}
\phi_{1}-d_{1} \\
\phi_{2}-d_{2} \\
-\frac{b_{1}^{3}}{b_{1}^{2}+\rho \sigma_{D}^{2}} \\
-\frac{b_{2}^{3}}{b_{2}^{2}+\rho \sigma_{D}^{2}}
\end{array}\right]=\left[\begin{array}{cccc}
1 / \phi_{1} & 0 & 0 & 0 \\
0 & 1 / \phi_{2} & 0 & 0 \\
-\frac{b_{1} d_{1}}{\phi_{1}\left(b_{1}^{2}+\rho \sigma_{D}^{2}\right)} & 0 & \frac{b_{1}}{b_{1}^{2}+\rho \sigma_{D}^{2}} & 0 \\
0 & -\frac{b_{2} d_{2}}{\phi_{2}\left(b_{2}^{2}+\rho \sigma_{D}^{2}\right)} & 0 & -\frac{b_{2} d_{2}}{b_{2}^{2}+\rho \sigma_{D}^{2}}
\end{array}\right]\left[\begin{array}{c}
\phi_{1}\left(\phi_{1}-d_{1}\right) \\
\phi_{2}\left(\phi_{2}-d_{2}\right) \\
b_{1}^{2}+d_{1}\left(\phi_{1}-d_{1}\right) \\
b_{2}^{2}+d_{2}\left(\phi_{2}-d_{2}\right)
\end{array}\right]
$$

where the first matrix is $\Psi_{\mathrm{PBO}} \Xi_{\mathrm{PBO}}^{-1}$ and the column vector is $y^{T} B \Psi_{\mathrm{PBO}}$. For a FBO this reads

$$
z_{\mathrm{FBO}}=\left[\begin{array}{c}
\phi_{1}-d_{1} \\
\phi_{2}-d_{2} \\
-\frac{b_{1}^{3}}{b_{1}^{2}+\rho \sigma_{D}^{2}} \\
-\frac{b_{2}^{3}}{b_{2}^{2}+\rho \sigma_{D}^{2}}
\end{array}\right]=\left[\begin{array}{cccc}
1 / \phi_{1} & 0 & 0 & 0 \\
0 & 1 / \phi_{2} & 0 & 0 \\
0 & 0 & \frac{b_{1}}{b_{1}^{2}+\rho \sigma_{D}^{2}} & 0 \\
0 & 0 & 0 & -\frac{b_{2}}{b_{2}^{2}+\rho \sigma_{D}^{2}}
\end{array}\right]\left[\begin{array}{c}
\phi_{1}\left(\phi_{1}-d_{1}\right) \\
\phi_{2}\left(\phi_{2}-d_{2}\right) \\
-b_{1}^{2} \\
-b_{2}^{2}
\end{array}\right]
$$

where the first matrix is $\Psi_{\mathrm{FBO}} \Xi_{\mathrm{FBO}}^{-1}$ and the column vector is $y^{T} B \Psi_{\mathrm{FBO}}$. This proves equivalence. $^{3}$

\section{Result 5}

This result uses the equivalence result to assess whether a small change in the spillover parameters increases effort differently for the two organizations. The approach is to approximate the solution using the equivalence result given above and then take the difference between the effort under a PBO and FBO. The results are derived by normalization so that $\phi_{i}=1$. Results are shown in Table 2 and are only given for one product and environmental damage, as the results are identical. The difference between the effort vectors for the organizational structures is assessed by approximating the optimal effort by a first Taylor series approximation and taking the difference between the effort vector for a PBO and FBO. Effort is approximated at the point of equivalence where $z_{\mathrm{PBO}}=z_{\mathrm{FBO}}$ and the spillovers are zero.

For the profit spillover:

$$
z_{\mathrm{PBO}}-z_{\mathrm{FBO}} \approx\left[\begin{array}{c}
\frac{\eta_{i} b_{i} \rho \sigma_{D}^{2}}{b_{i}^{2}+\rho \sigma_{D}^{2}} \\
\frac{\eta_{i} \rho \sigma_{D}^{2}\left(\left(d_{1}-1\right) \rho \sigma_{D}^{2}-b_{i}\left(d_{i}+1\right)\right)}{b_{i}^{2}+\rho \sigma_{D}^{2}},
\end{array}\right],
$$

which indicates that if there is a positive (negative) parameter $\eta_{i}$ between profit and environmental effort, a PBO will have a higher (lower) production and environmental effort than a FBO. The numerical example indicates that the firm and society would favour a PBO. For the environmental spillover:

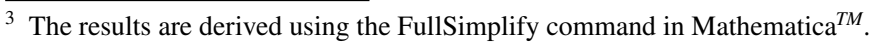




$$
z_{\mathrm{PBO}}-z_{\mathrm{FBO}} \approx\left[\begin{array}{c}
0 \\
\frac{2 b_{i}^{2} \rho \sigma_{D}^{2} s b_{i j}}{b_{i}^{2}+\rho \sigma_{D}^{2}}
\end{array}\right],
$$

which indicates that environmental effort is higher in a FBO than a PBO if there is a negative (i.e., damage-reducing) spillover. There is no difference in production effort.

Open Access This article is licensed under a Creative Commons Attribution 4.0 International License, which permits use, sharing, adaptation, distribution and reproduction in any medium or format, as long as you give appropriate credit to the original author(s) and the source, provide a link to the Creative Commons licence, and indicate if changes were made. The images or other third party material in this article are included in the article's Creative Commons licence, unless indicated otherwise in a credit line to the material. If material is not included in the article's Creative Commons licence and your intended use is not permitted by statutory regulation or exceeds the permitted use, you will need to obtain permission directly from the copyright holder. To view a copy of this licence, visit http://creativecommons.org/licen ses/by/4.0/.

\section{References}

Arlen J, MacLeod WB (2005) Torts, expertise, and authority: liability of physicians and managed care organizations. RAND J Econ 36(3):494-519

Berrone P, Gomez-Mejia LR (2009) Environmental performance and executive compensation: an integrated agency-institutional perspective. Acad Manag J 52(1):103-126

Besanko D, Régibeau P, Rockett KE (2005) A multi-task principal-agent approach to organizational form. J Ind Econ 53(4):437-467

Coase R (1960) The problem of social cost. J Law Econ 3:1-44

Corts KS (2006) The interaction of task and asset allocation. Int J Ind Organ 24(5):887-906

Elson CM, Ferrere CK, Goossen NJ (2015) The bug at Volkswagen: lessons in co-determination, ownership and board structure. J Appl Corp Financ 27(4):36-43

Gabel HL, Sinclair-Desgagné B (1993) Managerial incentives and environmental compliance. J Environ Econ Manag 24(3):229-240

Gautier A, Wauthy X (2007) Teaching versus research: a multi-tasking approach to multi-department universities. Eur Econ Rev 51(2):273-295

Holmstrom B (1979) Moral hazard and observability. Bell J Econ 10(1):74-91

Holmstrom B, Milgrom P (1987) Aggregation and linearity in the provision of intertemporal incentives. Econometrica 55(2):303-328

Holmstrom B, Milgrom P (1991) Multitask principal-agent analysis: incentives contracts, asset ownership and job design. J Law Econ Organ 7:24-52

Kornhauser LA (1982) An economic analysis of the choice between enterprise and personal liability for accidents. Calif Law Rev 70(6):1345-1392

Kraakman RH (2000) Vicarious and corporate civil liability. In: Bouckaert B, De Geest G (eds) Encyclopedia of law and economics, vol II. Edward Elgar Publishing, Cheltenham

Langevoort DC (2018) Behavioral ethics, behavioral compliance. In: Arlen J (ed) Research handbook on corporate crime and financial misdealing, vol 11. Edward Elgar Publishing, Cheltenham

Martin R, Muûls M, de Preux LB, Wagner UJ (2012) Anatomy of a paradox: management practices, organizational structure and energy efficiency. J Environ Econ Manag 63(2):208-223

Miller GP (2018) The compliance function: an overview. In: Gordon JN, Ringen W-G (eds) The Oxford handbook of corporate law and governance. Oxford University Press, Oxford

Segerson K, Tietenberg T (1992) The structure of penalties in environmental enforcement: an economic analysis. J Environ Econ Manag 23(2):179-200

Sinclair-Desgagné B (1994) The first-order approach to multi-signal principal-agent problems. Econometrica 62(2):459-465 
Sinclair-Desgagné B, Gabel HL (1997) Environmental auditing in management systems and public policy. J Environ Econ Manag 33(3):331-346

Sykes AO (1984) The economics of vicarious liability. Yale Law J 93(7):1231-1280

Sykes AO (1988) The boundaries of vicarious liability: an economic analysis of the scope of employment rule and related legal doctrines. Harv Law Rev 101(3):563-609

Walls JL, Berrone P, Phan PH (2012) Corporate governance and environmental performance: is there really a link? Strateg Manag J 33(8):885-913

Publisher's Note Springer Nature remains neutral with regard to jurisdictional claims in published maps and institutional affiliations. 